\title{
Compensation between resolved wave driving and parameterized orographic gravity wave driving of the Brewer-Dobson circulation and its response to climate change
}

Article

Published Version

Sigmond, M. and Shepherd, T. G. (2014) Compensation between resolved wave driving and parameterized orographic gravity wave driving of the Brewer-Dobson circulation and its response to climate change. Journal of Climate, 27 (14). pp. 5601-5610. ISSN 1520-0442 doi: https://doi.org/10.1175/JCLID-13-00644.1 Available at https://centaur.reading.ac.uk/37156/

It is advisable to refer to the publisher's version if you intend to cite from the work. See Guidance on citing.

To link to this article DOI: http://dx.doi.org/10.1175/JCLI-D-13-00644.1

Publisher: American Meteorological Society

All outputs in CentAUR are protected by Intellectual Property Rights law, including copyright law. Copyright and IPR is retained by the creators or other copyright holders. Terms and conditions for use of this material are defined in the End User Agreement. 


\section{www.reading.ac.uk/centaur}

\section{CentAUR}

Central Archive at the University of Reading

Reading's research outputs online 


\title{
Compensation between Resolved Wave Driving and Parameterized Orographic Gravity Wave Driving of the Brewer-Dobson Circulation and Its Response to Climate Change
}

\author{
MiCHAEL SIGMOND \\ Canadian Centre for Climate Modelling and Analysis, Environment Canada, Victoria, British Columbia, Canada \\ THEODORE G. SHEPHERD \\ Department of Meteorology, University of Reading, Reading, United Kingdom
}

(Manuscript received 21 October 2013, in final form 18 February 2014)

\begin{abstract}
Following recent findings, the interaction between resolved (Rossby) wave drag and parameterized orographic gravity wave drag (OGWD) is investigated, in terms of their driving of the Brewer-Dobson circulation (BDC), in a comprehensive climate model. To this end, the parameter that effectively determines the strength of OGWD in present-day and doubled $\mathrm{CO}_{2}$ simulations is varied. The authors focus on the Northern Hemisphere during winter when the largest response of the BDC to climate change is predicted to occur. It is found that increases in OGWD are to a remarkable degree compensated by a reduction in midlatitude resolved wave drag, thereby reducing the impact of changes in OGWD on the BDC. This compensation is also found for the response to climate change: changes in the OGWD contribution to the BDC response to climate change are compensated by opposite changes in the resolved wave drag contribution to the BDC response to climate change, thereby reducing the impact of changes in OGWD on the BDC response to climate change. By contrast, compensation does not occur at northern high latitudes, where resolved wave driving and the associated downwelling increase with increasing OGWD, both for the present-day climate and the response to climate change. These findings raise confidence in the credibility of climate model projections of the strengthened BDC.
\end{abstract}

\section{Introduction}

The Brewer-Dobson circulation (BDC) is the stratospheric meridional overturning circulation characterized by upward mean motion in the tropics and poleward and descending mean motion in the middle and high latitudes. Although tracer distributions are also determined by mixing, the mean mass overturning is a tracerindependent quantity and is, thus, usually considered as the definition of the BDC (e.g., Shepherd 2007). Climate models consistently predict a strengthening of the BDC in response to (greenhouse gas induced) climate change of about $2 \%$ per decade (Butchart et al. 2006, 2010). A strengthening of the BDC will accelerate the recovery of stratospheric ozone by speeding up the removal of

Corresponding author address: Michael Sigmond, Canadian Centre for Climate Modelling and Analysis, University of Victoria, P.O. Box 1700 STN CSC, Victoria, BC V8W 2Y2, Canada. E-mail: michael.sigmond@ec.gc.ca halogens (Butchart and Scaife 2001). It will change the latitudinal distribution of stratospheric ozone (Shepherd 2008; WMO 2011) and, consequently, the spatial distribution of harmful shortwave radiation that reaches the surface (Hegglin and Shepherd 2009; WMO 2011). A strengthened BDC would also increase the amount of stratospheric ozone that is transported to the troposphere, which could have detrimental effects for air quality (Hegglin and Shepherd 2009).

It is well known that the BDC is driven by stratospheric wave drag provided by the breaking of Rossby waves (also referred to as "resolved" waves as they are explicitly simulated by current climate models) and gravity waves (also referred to as "parameterized" waves as their effects must be parameterized owing to their small length scales). In the lower stratosphere, the dominant gravity wave contribution to the driving of the BDC is believed to come from orographic gravity waves (Butchart et al. 2011). Although the gravity wave component of the BDC cannot be directly inferred from 
observations, the multimodel mean contribution to the net mass transport across $70 \mathrm{hPa}$ (the usual measure of the total stratospheric overturning) from resolved waves is about $70 \%$ (Butchart et al. 2011), which agrees well with estimates from reanalyses (Randel et al. 2008; Butchart et al. 2011) and implies a contribution of about $30 \%$ from gravity waves. However, the relative importance of resolved and parameterized waves varies considerably between different climate models. Butchart et al. (2011) showed that in the current generation of chemistry-climate models the contribution of parameterized waves to the net mass overturning varies between roughly $0 \%$ and $50 \%$ and that of resolved waves between about $50 \%$ and $100 \%$. Similar ranges were obtained with an earlier generation of models (Butchart et al. 2010). Uncertainty regarding the drivers of the $\mathrm{BDC}$ response to climate change is even larger, with the contribution of parameterized waves ranging from roughly $20 \%$ to $95 \%$ (Butchart et al. 2010). This large variation has been interpreted as suggesting that models disagree on the mechanism responsible for the BDC trend, casting doubt on the credibility of the model projections of the BDC and its corresponding impacts (WMO 2011).

On the other hand, Butchart et al. (2010) showed that, despite the large range of wave drag contributions, the models tend to agree quite well on the strength of the BDC, as well as (albeit to a lesser extent) on the predicted BDC trends themselves. Models with a large parameterized wave drag contribution to the BDC trend tend to have a small contribution from resolved wave drag (and vice versa). However, this relationship is based on only a few models, and there are models with circulation responses that are not in line with this relationship. Because of the many differences between the models used in Butchart et al. (2010) (including physics, chemistry, and resolution) it is not possible to draw firm conclusions. To address this question, it is necessary to perform controlled experiments in which either the resolved or parameterized waves are systematically perturbed. Such experiments have been performed by McLandress and McFarlane (1993) for the mesosphere and McLandress et al. (2012) for the Southern Hemisphere, but Cohen et al. (2013) were the first to address this in the context of the driving of the BDC. Employing an idealized atmospheric general circulation model (AGCM) Cohen et al. (2013) identified a compensation between resolved and parameterized wave driving of the BDC in (present day) control simulations. They found that, when parameterized wave drag was perturbed, the resolved wave drag changed in the opposite direction so that the strength of the BDC remained unchanged. If such compensation also occurred for the response to climate change in comprehensive climate models, this could have far-reaching consequences for the interpretation of climate model projections. In particular, it would imply that the large variation in the relative wave drag contributions to the BDC trend would not represent a significant source of uncertainty, alleviating some of the concerns regarding the credibility of model projections of the BDC. It would also imply that the traditional decomposition of the BDC and its response to climate change into resolved and parameterized wave parts would be misleading.

In this study, we investigate whether the compensation between resolved and parameterized wave driving of the BDC identified in an idealized model in Cohen et al. (2013) is also found in a comprehensive model. In addition we examine, for the first time with controlled experiments, if such compensation also occurs in the response to climate change. This is accomplished by varying a parameter in the parameterization scheme for orographic gravity waves that effectively controls the orographic gravity wave drag (OGWD) strength in the present day and doubled $\mathrm{CO}_{2}$ climate. These simulations have been considered previously in Sigmond and Scinocca (2010, hereafter SS10), who showed that the tropospheric response to climate change depends critically on the strength of OGWD, but here we focus on the response of the BDC. We show that a remarkable degree of compensation between resolved wave drag and OGWD occurs in the low to middle (but not high) latitudes for both the present-day climate and the response to $\mathrm{CO}_{2}$ doubling.

\section{Model and simulations}

We analyze the same simulations as those described in SS10, to which we refer the reader for details. We employ the Canadian Centre for Climate Modelling and Analysis third-generation atmospheric general circulation model (AGCM3) (Scinocca et al. 2008). The model has 32 levels from the surface to $1 \mathrm{hPa}$ at T63 horizontal spectral resolution. This configuration of the model does not include a parameterization scheme for nonorographic gravity waves and has a rather poor stratospheric resolution, but the relevant processes for this study occur in the lower stratosphere and very similar results to those shown below were found in the same type of simulations with the Canadian Middle Atmosphere Model (CMAM), the middleatmosphere version of AGCM3 (not shown). Forty-year time-slice simulations were run for the present-day climate (referred to as $1 \times \mathrm{CO}_{2}$ or control runs) and the doubled $\mathrm{CO}_{2}$ climate $\left(2 \times \mathrm{CO}_{2}\right)$. In the $2 \times \mathrm{CO}_{2}$ runs 
the atmospheric $\mathrm{CO}_{2}$ is doubled, the sea surface temperature field is perturbed with a monthly varying anomaly calculated from an ensemble average over models that contributed to phase 3 of the Coupled Model Intercomparison Project (CMIP3), and the sea ice field is not perturbed relative to the $1 \times \mathrm{CO}_{2}$ simulations (details in Sigmond et al. 2008). The response to climate change is defined as the difference between the climatologies of the $1 \times \mathrm{CO}_{2}$ and $2 \times \mathrm{CO}_{2}$ simulations. We focus on the Northern Hemisphere $(\mathrm{NH})$ in boreal winter [December-February (DJF)] as the BDC response to climate change maximizes in the $\mathrm{NH}$ in that season (Butchart et al. 2010).

The model includes the Scinocca and McFarlane (2000) parameterization scheme for orographic wave drag. We vary the internal parameter $G(\nu)$ (hereafter referred to as $G$ ), which is a multiplicative factor that scales the amount of gravity wave momentum flux produced by the interaction of the low-level circulation with the topography. A factor similar to $G$ is common to all OGWD schemes currently used in comprehensive climate models and effectively controls the strength of OGWD. We consider the simulations with $G=0.25$ and 1.0, which SS10 referred to as the WEAK and STRONG (drag) cases. The $G=0.25$ setting is essentially equivalent to that used in CMAM for the purpose of polarozone studies, while the $G=1.0$ setting is that used in the operational AGCM3 (Scinocca et al. 2008). It is important to realize that $G$ is not well constrained due to the lack of global gravity wave observations and that both $G=0.25$ and 1.0 settings yield reasonable presentday simulations, with $G=0.25$ having smaller biases in lower stratospheric temperature and $G=1.0$ having smaller biases in mean sea level pressure. As we will see in the next section, the OGWD contribution to the BDC trend in NH winter (DJF) varies between $-10 \%$ for $G=$ 0.25 and $68 \%$ for $G=1.0$, more or less covering the range in OGWD contributions to the BDC trend simulated in chemistry-climate models (Butchart et al. 2010). In the next section we investigate whether changes in the OGWD are compensated by opposite changes in the resolved wave drag, thereby reducing the impact of the OGWD changes on the total BDC, both for the present-day climate and in the context of the response to climate change. To investigate the robustness and linearity of the results we analyze new present-day and doubled $\mathrm{CO}_{2}$ simulations with $G=0$ (effectively turning off the OGWD parameterization scheme), $G=0.5$, and $G=0.75$. In the remainder of this paper "response" is used only in the context of the response to climate change, whereas "change" is associated with the difference between different settings of $G$.

\section{Results}

Before considering the interaction between resolved and parameterized orographic gravity waves, we first describe general features of the BDC for the simulations with $G=0.25$ (the CMAM setting). For this case, the left panels of Fig. 1 show the residual vertical velocity $\bar{w}^{*}$ at $70 \mathrm{hPa}$, a diagnostic often used to characterize the latitudinal structure of the BDC. The black solid line shows $\bar{w}^{*}$ computed via the direct method [using Eqs. (1) and (2) of McLandress and Shepherd (2009)]. For the $1 \times \mathrm{CO}_{2}$ climate (Fig. 1a) one can clearly identify the familiar upwelling (positive $\bar{w}^{*}$ ) in the tropics and downwelling (negative $\bar{w}^{*}$ ) in the extratropics that defines the BDC. The vertical dashed lines represent the so-called "turn around" latitude, the location at which $\bar{w}^{*}$ is zero and the tropical upwelling changes to extratropical downwelling. We apply the downward control principle of Haynes et al. (1991) to quantify the separate wave drag contributions to $\bar{w}^{*}$ [using Eq. (3) of McLandress and Shepherd (2009)]. Note that downward control cannot be applied in the tropics. The sum of the contribution of OGWD (red line) and of resolved wave drag [quantified by the Eliassen-Palm (EP) flux divergence and denoted by the blue line] is shown by the gray line and corresponds closely to the actual $\bar{w}^{*}$ poleward of the turn-around latitude, hence fully accounting for the extratropical downwelling and thus (by mass conservation) also for the tropical upwelling. Consistent with previous studies (e.g., McLandress and Shepherd 2009) we find that resolved wave drag is the main driver of the downwelling in the region north of $45^{\circ} \mathrm{N}$. The OGWD contribution is characterized by a meridional dipole centered around $35^{\circ} \mathrm{N}$, with upwelling equatorward of $35^{\circ} \mathrm{N}$ and downwelling poleward of $35^{\circ} \mathrm{N}$. This circulation is consistent with a region of large OGWD at the upper and poleward flank of the subtropical jet (Fig. 1a of SS10). The net downward mass flux in the extratropics [which is proportional to $\bar{w}^{*}$ integrated between the turn-around latitude and the pole and is calculated as in Holton (1990)] is here used as a proxy for the strength of the BDC. The OGWD contribution to the net downward mass flux is $28 \%$, which lies in the middle of the range found in chemistry-climate models (Butchart et al. 2011 ) and is similar to the value of about $30 \%$ inferred from reanalyses (Randel et al. 2008; Butchart et al. 2011).

The response to climate change (Fig. 1d) shows the robustly documented strengthening of the BDC, with increased upwelling (positive $\Delta \bar{w}^{*}$ ) in the tropics and increased downwelling (negative $\Delta \bar{w}^{*}$ ) in the extratropics. The region of tropical upwelling narrows in 
$\mathbf{G}=\mathbf{0 . 2 5}$

(a)

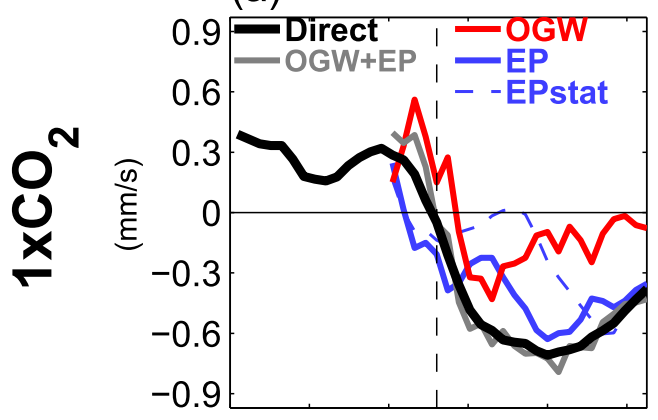

$20 \mathrm{~S}$ EQ $20 \mathrm{~N} 40 \mathrm{~N} 60 \mathrm{~N} 80 \mathrm{~N}$

(d)

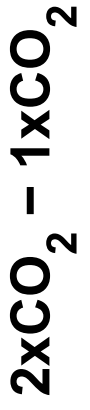

$\underbrace{0}{ }^{N}$

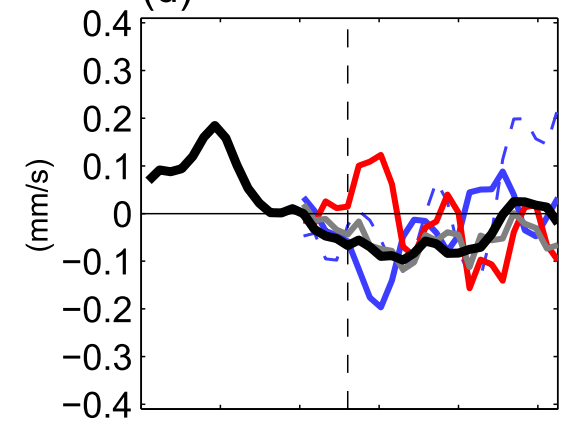

20 S EQ $20 \mathrm{~N} 40 \mathrm{~N} 60 \mathrm{~N} 80 \mathrm{~N}$ latitude (b)

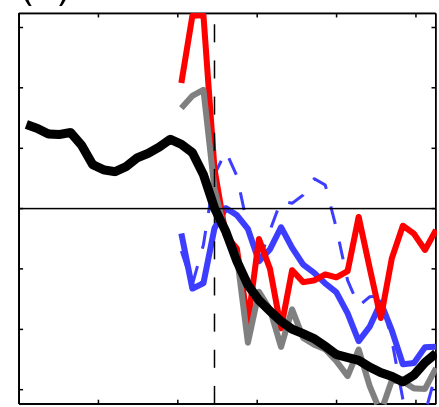

20S EQ 20N 40N 60N 80N

(e)

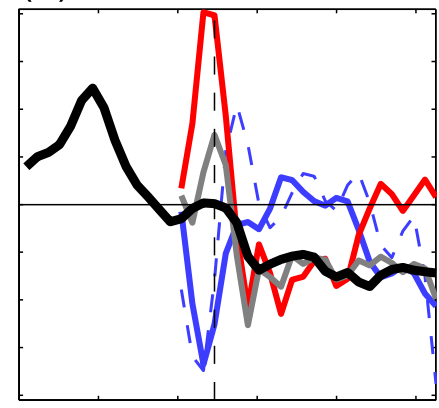

20 S EQ 20N 40N 60N 80N latitude
$\mathbf{G}=1.0-\mathbf{G}=0.25$

(c)

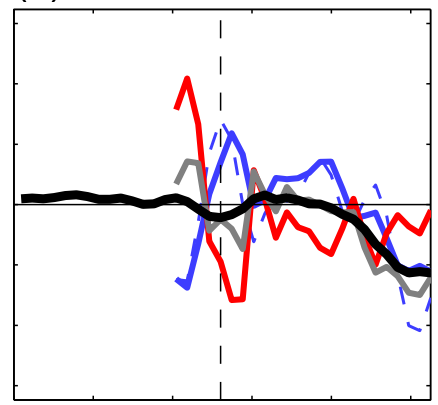

$20 S$ EQ 20N 40N 60N 80N

(f)

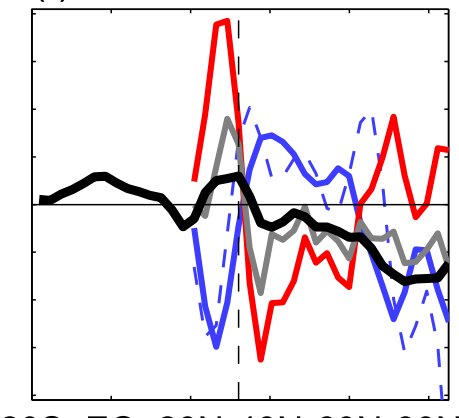

20 S EQ 20N 40N 60N 80N latitude

FIG. 1. The residual vertical velocity at $70 \mathrm{hPa}$ in $\mathrm{NH}$ winter (DJF) computed via the direct method, and from downward control using parameterized wave drag (OGW), resolved wave drag (EP), and resolved stationary wave drag (EPstat) for (left) $G=0.25$ and (center) $G=1.0$, and (right) the difference between $G=1.0$ and 0.25 , for (a)-(c) $1 \times \mathrm{CO}_{2}$ and (d)-(f) the response to climate change. The vertical dashed lines represent the turn-around latitude in the $1 \times \mathrm{CO}_{2}$ climate for $G=0.25 \mathrm{in}$ (left) and (right), and $G=1.0 \mathrm{in}$ (center).

response to climate change, a feature that has also been found in other climate models (e.g., Li et al. 2010). The downward control analysis reveals an interesting anticorrelation between the resolved wave drag and OGWD [previously noted by McLandress and Shepherd (2009)], which is suggestive of a strong coupling between resolved and orographic gravity waves. The response to climate change of the net downward mass flux is mainly due to resolved wave drag changes, with OGWD having a small negative contribution $(-10 \%)$. In terms of the importance of OGWD changes for the BDC trend, the $G=0.25$ case thus represents the lower end of the range found in chemistry-climate models (Butchart et al. 2010).

We next investigate the effect of increasing $G$ (or equivalently: the strength of OGWD) on resolved waves and the BDC. For the $1 \times \mathrm{CO}_{2}$ climate (Figs. 1b,c) an increase of $G$ from 0.25 to 1.0 results in an amplification of the OGWD-induced meridional circulation centered around $35^{\circ} \mathrm{N}$ (which is consistent with an amplification of the OGWD maximum at the upper and poleward flank of the subtropical jet as shown in Figs. $1 \mathrm{~b}$ and $1 \mathrm{c}$ of SS10). As the center of this dipole is located close to the turn-around latitude, this OGWD change would suggest a substantial BDC strengthening with increasing $G$. The OGWD contribution to the strength of the BDC (in terms of the net downward mass flux) increases from $28 \%$ for $G=0.25$ to $57 \%$ for $G=1.0$ (which is at the high end of the range found in chemistry-climate models) and would, in the absence of resolved wave drag changes, result in a BDC that is $35 \%$ stronger in the $G=1.0$ relative to the $G=0.25$ case. We find, however, that the midlatitude $\bar{w}^{*}$ is virtually insensitive to changes in the OGWD (see black line in Fig. 1c). Changes in the OGWD contribution to $\bar{w}^{*}$ are almost entirely compensated by opposite contributions from resolved waves. The compensation mainly comes from stationary waves (indicated by the dashed blue lines) and does not occur at high latitudes (north of about $60^{\circ} \mathrm{N}$ ). We thus find that the compensation previously identified in an idealized AGCM (Cohen et al. 2013) also occurs in our 
comprehensive AGCM, and that the compensation is limited to middle latitudes. As a result of the lack of compensation at high latitudes (which will be discussed further below), the net downward mass flux is $9 \%$ higher in the $G=1.0$ relative to the $G=0.25$ case. We note that, while compensation by resolved waves leads to a small $\bar{w}^{*}$ change, the zonal-mean zonal wind is sensitive to changes in $G$ (see Fig. 3 of SS10). This is consistent with the findings of McLandress and McFarlane (1993) and Cohen et al. (2013) and suggests that the zonal-mean zonal wind is more sensitive to small changes in the momentum budget than is the residual circulation.

Similar results are found for the response to climate change (Figs. 1e,f). For the $G=1.0$ case the strengthening of the upper flank of the subtropical jet resulting from tropospheric warming (Fig. 3h of SS10) allows more orographic gravity wave flux to reach the base of the BDC, as was also shown by Li et al. (2008) and McLandress and Shepherd (2009). In response to $\mathrm{CO}_{2}$ doubling this leads to increased OGWD induced upwelling equatorward of $35^{\circ} \mathrm{N}$ and increased OGWDinduced downwelling poleward of $35^{\circ} \mathrm{N}$, a response that was not found for the $G=0.25$ case. The OGWD contribution to the BDC strengthening in response to climate change increases from $-10 \%$ for $G=0.25$ to $+68 \%$ for $G=1.0$ (which is at the middle to high end of the range found in chemistry-climate models). This would, in the absence of changes in the response of resolved waves, result in a BDC response to climate change that is $127 \%$ stronger in the $G=1.0$ compared to the $G=0.25$ case. As with the control climate we find, however, that the midlatitude $\bar{w}^{*}$ response to climate change is virtually insensitive to changes in $G$ (see black line in Fig. 1f), particularly for the region south of $52^{\circ} \mathrm{N}$. Figure 1f shows that changes in the OGWD are almost entirely compensated by opposite changes in the (stationary) resolved wave drag. Such compensation does not occur at high latitudes. While the resolved wave drag and OGWD changes in Fig. 1f are anticorrelated up to the pole, the magnitudes are different, which causes the high-latitude $\bar{w}^{*}$ response to climate change to be weaker in the $G=0.25$ relative to the $G=1.0$ case (see black line in Fig. 1f). This lack of high-latitude compensation implies that the shape of the BDC response to climate change is different for the two $G$ settings: the $\bar{w}^{*}$ response to climate change is limited to low to middle latitudes in the $G=0.25$ case (Fig. 1d) but extends to the pole in the $G=1.0$ case (Fig. 1e). In conclusion, we find that the midlatitude compensation and lack of high-latitude compensation identified for the present-day climate also occurs in the response to climate change.
The latitude-height distribution of the wave drag response to increasing $G$ is further investigated in Fig. 2. For the $1 \times \mathrm{CO}_{2}$ climate, Fig. 2a shows the increase of OGWD near $35^{\circ} \mathrm{N}, 70 \mathrm{hPa}$ and the resulting meridional circulation anomaly centered around $35^{\circ} \mathrm{N}$. At midlatitudes, changes in the resolved wave drag [represented by the Eliassen-Palm flux divergence (EPFD), Fig. 2b] nearly cancel out the OGWD changes. Such compensation does not occur at high latitudes where a substantial increase in (negative) resolved wave drag is found. This high-latitude resolved wave drag increase was shown by SS10 to be the result of OGWD induced changes in the basic state and will be discussed further in section 4. The increased high-latitude resolved wave driving implies increased downwelling. By mass continuity this increased high-latitude downwelling must be compensated by increased upwelling, which occurs in the deep tropics as revealed by Fig. 2c. For the response to climate change, the second row of Fig. 2 also shows the compensation that occurs between resolved wave drag and OGWD at midlatitudes, and the lack of such compensation for the high latitudes. The high-latitude resolved wave drag response was also discussed by SS10 and will be discussed further in section 4. This lack of compensation implies an increased high-latitude downwelling response to climate change, which is accompanied by an enhanced upwelling response in the deep tropics (Fig. 2f).

The EPFD change with increasing $G$ (Figs. 2b,e) is repeated in Figs. 3a and 3b. We wish to understand why the increase in $G$ is associated with a decrease in resolved wave driving (or equivalently, an increase of EPFD) within the regions delineated by the orange boxes. To learn more, we present an EP flux budget for these midlatitude lower stratospheric boxes, following Kushner and Polvani [2004, their Eq. (7)] and SS10. The red arrows and associated numbers across the sides of the box represent the integrated EP flux difference through each side, while the red numbers within the box represent the difference in the area-mean momentum deposition associated with the resolved waves, and equals (to within round-off error) the sum of the flux differences through the sides. For the $1 \times \mathrm{CO}_{2}$ climate, the budget shows that the lower stratospheric midlatitude resolved wave driving decreases by $2.8 \times 10^{4} \mathrm{~kg} \mathrm{~m} \mathrm{~s}^{-4}$, with about $70 \%$ of this decrease $\left(2.2 \times 10^{4} \mathrm{~kg} \mathrm{~m} \mathrm{~s}^{-4}\right)$ resulting from decreased EP flux from high latitudes, and about $30 \%\left(1.0 \times 10^{4} \mathrm{~kg} \mathrm{~m} \mathrm{~s}^{-4}\right)$ resulting from decreased EP flux from below. For the response to climate change, the wave driving in the lower stratospheric box decreases by $0.7 \times 10^{4} \mathrm{~kg} \mathrm{~ms}^{-4}$ and is explained by a substantial decrease of EP flux from high latitudes $\left(1.4 \times 10^{4} \mathrm{~kg} \mathrm{~m} \mathrm{~s}^{-4}\right)$. We note that the EP flux from 


\section{OGWD}

(a)

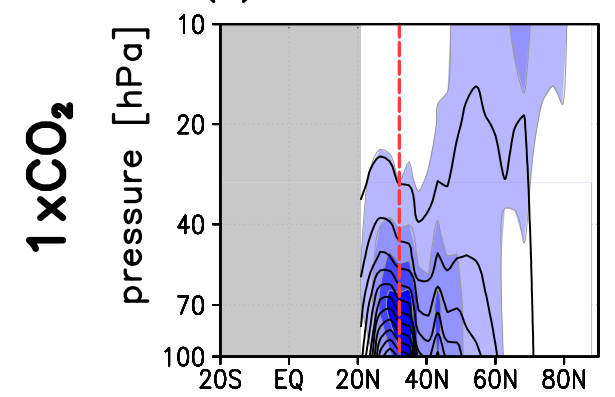

(d)

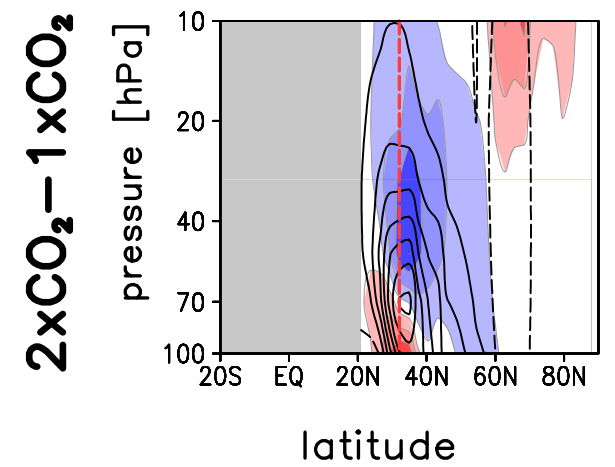

EPFD

(b)
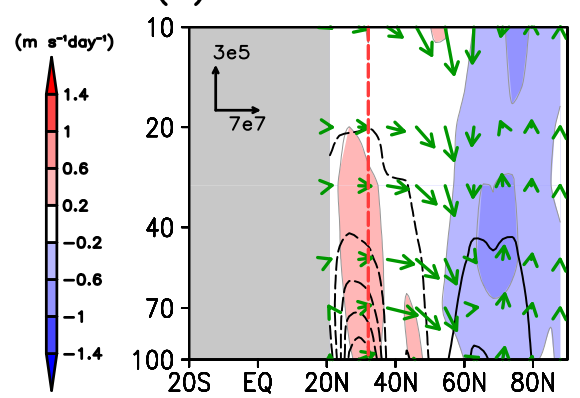

(e)
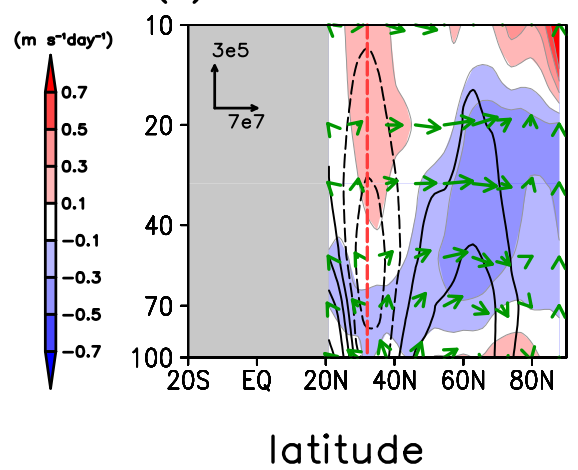

(c)

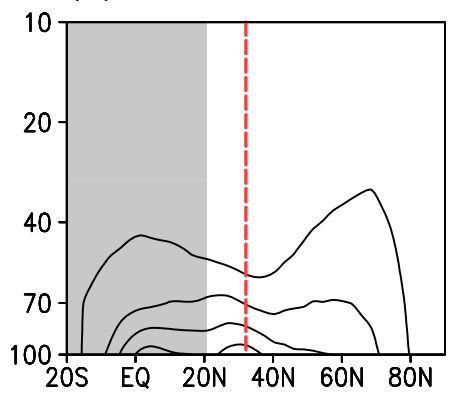

(f)

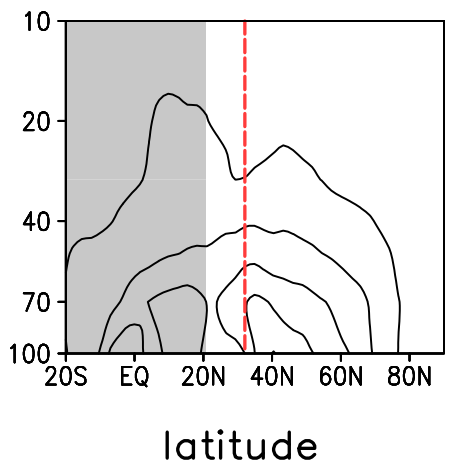

FIG. 2. The change with increasing $G$ from 0.25 to 1.0 of (left) OGWD (shading) and associated mass streamfunction (contours), (center) EP flux divergence and associated mass streamfunction, and (right) the total mass streamfunction for (a) $-(\mathrm{c}) 1 \times \mathrm{CO}_{2}$ and (d)-(f) the response to climate change. All plots are for NH winter (DJF). The green vectors in (center) represent the EP flux vectors divided by density ( $\mathrm{scale}$ at top left of each panel, $\mathrm{kg} \mathrm{s}^{-2}$ ). The contour interval for the mass streamfunction is $10 \mathrm{~kg} \mathrm{~m}^{-1} \mathrm{~s}^{-1}$. The red vertical dashed line shows the turn-around latitude for $G=0.25$ and $1 \times \mathrm{CO}_{2}$.

below actually increases (by $0.8 \times 10^{4} \mathrm{~kg} \mathrm{~m} \mathrm{~s}^{-4}$ ), which acts to weaken the (negative) resolved wave drag response in the midlatitude lower stratosphere. These budgets and their relation to the zonal-mean zonal wind changes (depicted by the contours in Fig. 3) are discussed further in section 4 .

Our results are summarized and their robustness established in Fig. 4, which includes the results of three additional sets of $1 \times \mathrm{CO}_{2}$ and $2 \times \mathrm{CO}_{2}$ simulations (with $G=0,0.5$, and 0.75 ). For the $1 \times \mathrm{CO}_{2}$ climate Fig. 4a shows the mass streamfunction $\Psi$ at $70 \mathrm{hPa}$ evaluated at the turn-around latitude (which is proportional to the BDC strength as quantified by the net downward mass flux). While the OGWD contribution to the BDC increases substantially with increasing $G$, the BDC itself is comparatively insensitive owing to the compensating effect of resolved waves. Figure $4 \mathrm{~b}$ shows that the $\Psi$ difference between the turn-around latitude and $52^{\circ} \mathrm{N}$ (which is proportional to the net midlatitude downward mass flux) is virtually insensitive to changes in $G$, illustrating the nearly perfect compensation between OGWD and resolved wave drag at midlatitudes. Figure $4 \mathrm{c}$ shows that the OGWD contribution to the BDC response to climate change increases dramatically with increasing $G$ between $G=0.25$ and 0.75 . This is partly compensated by opposite changes in resolved waves (Fig. 4c), thereby limiting the sensitivity to $G$ of the BDC response to climate change. Figure $4 \mathrm{~d}$ shows that this compensation is nearly complete for the midlatitude component of the BDC.

\section{Summary and discussion}

Climate models consistently predict a strengthening of the stratospheric meridional overturning circulation known as the Brewer-Dobson circulation (BDC) in response to (greenhouse gas induced) climate change. Previous studies have shown that the relative contribution of resolved and parameterized waves to this strengthening of the BDC varies substantially between climate models, raising concerns that the modelpredicted response to climate change may not be reliable. Here we address this issue in a comprehensive AGCM by perturbing $G$, the parameter that effectively 

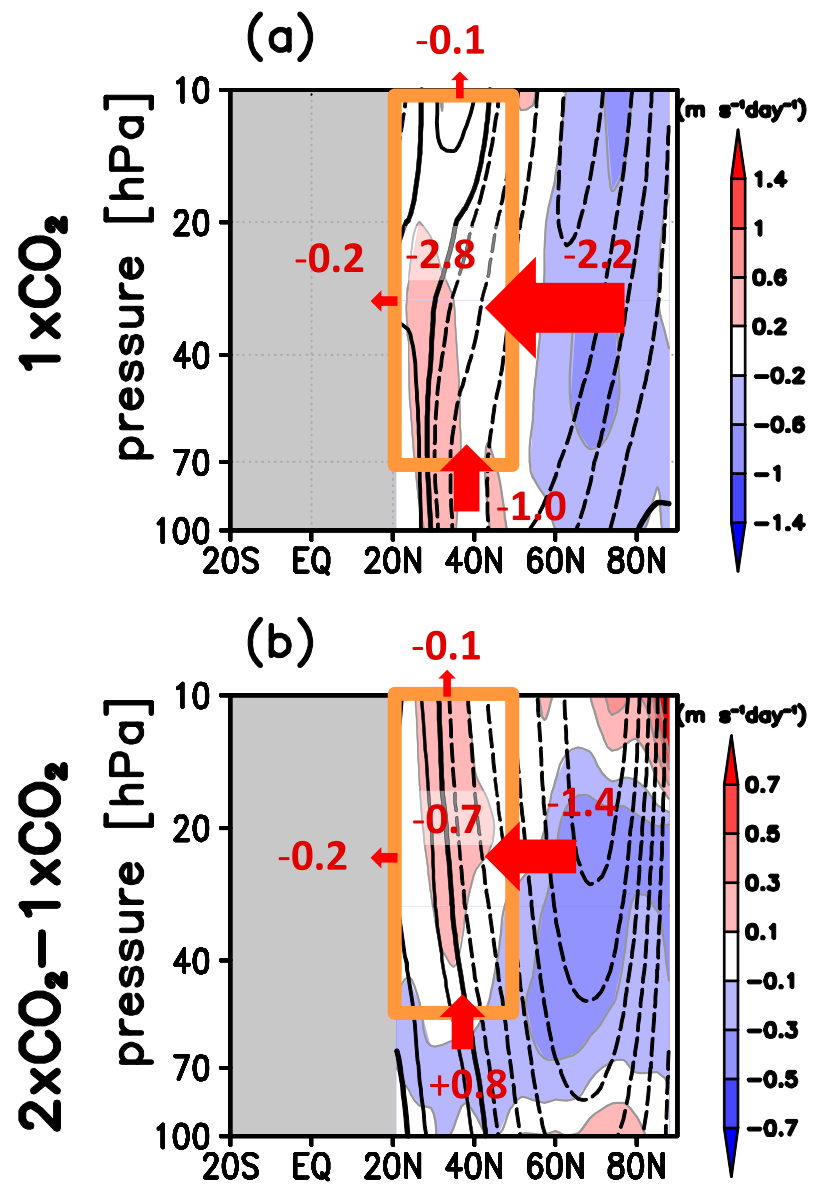

\section{latitude}

FIG. 3. The change with increasing $G$ from 0.25 to 1.0 of (shading) the EP flux divergence and (contours) the zonal-mean zonal wind for (a) $1 \times \mathrm{CO}_{2}$ and (b) the response to climate change. The contour interval of the zonal-mean zonal wind is $2 \mathrm{~m} \mathrm{~s}^{-1}$ (beginning with contours at $\pm 1 \mathrm{~m} \mathrm{~s}^{-1}$ ) with the thick solid line denoting $0 \mathrm{~m} \mathrm{~s}^{-1}$. In addition, a budget for resolved wave driving is presented for the regions delineated by the orange boxes. Red numbers across the box represent EP flux differences integrated over the box boundaries, and the red numbers in the box represent the resolved wave driving differences integrated over the box $\left(10^{4} \mathrm{~kg} \mathrm{~m} \mathrm{~s}^{-4}\right)$.

determines the strength of orographic gravity wave drag (OGWD), roughly spanning the range of OGWD contributions to the BDC found in current chemistryclimate models. We find that, in midlatitudes, increases in OGWD are almost entirely compensated by opposite changes in resolved wave drag. However, such compensation does not occur at high latitudes. Similar results are found for the response to climate change. An enhanced $G$ is associated with a larger OGWD contribution to the $\mathrm{BDC}$ response to climate change, but is at midlatitudes accompanied by a smaller resolved wave drag response so that the total midlatitude BDC response to climate change is insensitive to $G$. As for the control climate, such compensation was not found at high latitudes. Although the high-latitude circulation response is important at high latitudes, its contribution to the net mass overturning is comparatively small on account of the relatively small area of the polar cap compared to the tropics. We thus find that the strength of the BDC and its response to climate change is much more robust than might be expected from the large change in relative wave drag contributions as $G$ is varied. This is consistent with the fact that climate models tend to agree much better on the strength of the total BDC (and its response to climate change) than on the relative wave drag contributions. It also implies that the linear decomposition of the driving of the BDC into resolved and parameterized parts is misleading. This linear framework suggests that the resolved and parameterized waves act independently whereas the compensation documented here reveals strong interactions between the different wave driving components.

Cohen et al. (2013) found compensation between the effect of resolved wave drag and parameterized OGWD on the climatological BDC in an idealized AGCM (although in contrast to our study they found no circulation response, compensated or otherwise, at high latitudes). They argued that the compensation they found arose from instability of the wintertime upper stratospheric midlatitude flow, but we find no evidence that such a mechanism operates in our comprehensive AGCM. In particular, there are no regions of EP flux divergence in the wintertime stratosphere in our model, as would be required for instability. Instead, we argue that the compensation in the driving of the BDC that we find in the $1 \times \mathrm{CO}_{2}$ climate is primarily related to the same changes in planetary-wave propagation that lead to the high-latitude response (as discussed by SS10). The direct effect of increasing OGWD is to weaken the zonal winds in the upper flank of the subtropical jet (see the contours in Fig. 3a). SS10 showed that this zonal wind weakening changes the refractive properties for resolved waves in such a way that it is harder for planetary waves to propagate equatorward. SS10 argued that the resulting decrease of the EP flux from high latitudes into the midlatitude lower stratosphere explains the increased resolved wave driving at high latitudes (thus accounting for the lack of high-latitude compensation identified here). Here we show that the decrease of equatorward EP flux also accounts for about $70 \%$ of the midlatitude compensation by resolved waves (Fig. 3a). The OGWDinduced weakening of the lower stratospheric midlatitude winds also results in a lowering of the critical levels of planetary waves propagating up from below, allowing less waves to reach the lower stratosphere 
TURN

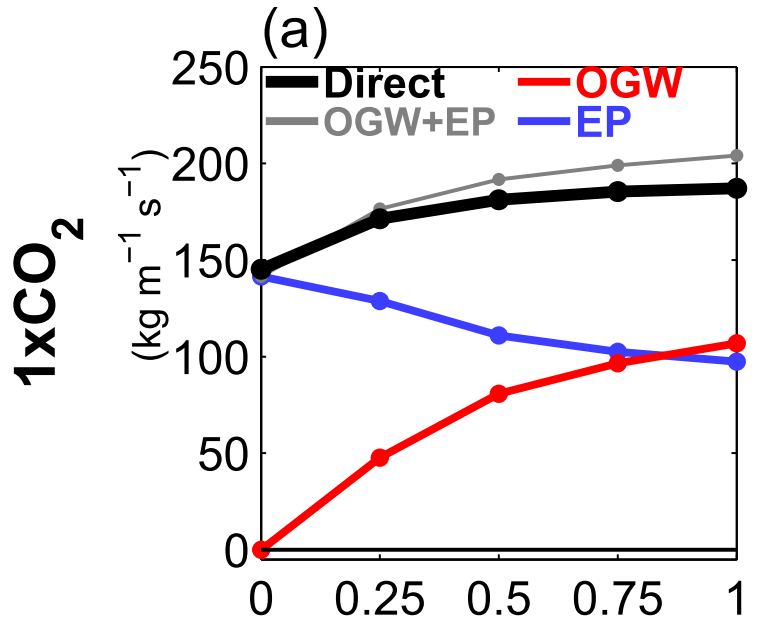

(c)

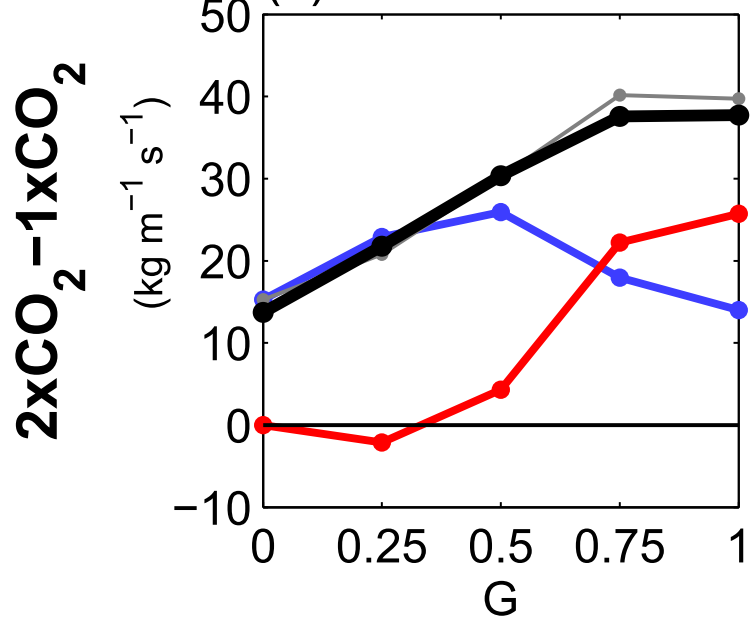

TURN-52N

(b)

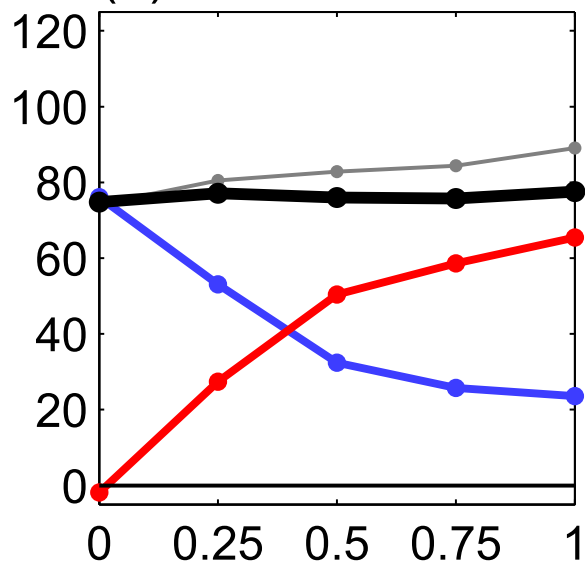

(d)

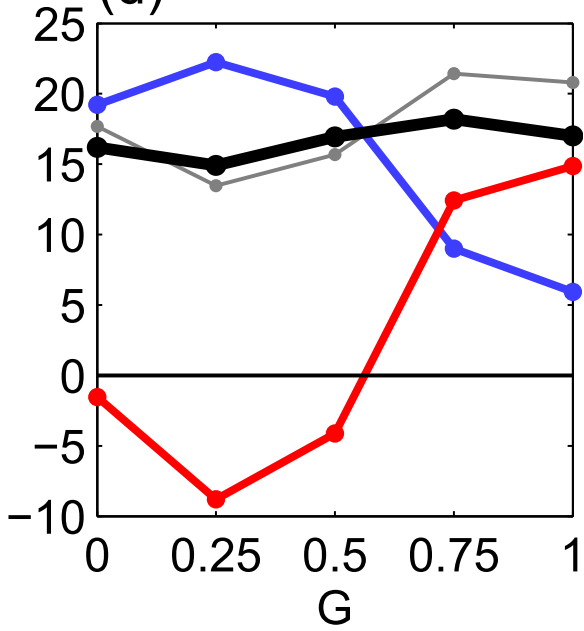

FIG. 4. (a),(c) The mass streamfunction $\Psi$ at $70 \mathrm{hPa}$ for NH winter (DJF) as a function of $G$ at the turn-around latitude, and (b),(d) the difference between $\Psi$ at the turn-around latitude and $52^{\circ} \mathrm{N}$ for (top) $1 \times \mathrm{CO}_{2}$ and (bottom) the response to climate change.

(Shepherd and McLandress 2011). As shown in Fig. 3a, this accounts for the other $30 \%$ of the midlatitude compensation by resolved waves.

Regarding the response to climate change, the impact of increasing $G$ differs in a fundamental way from its impact on the $1 \times \mathrm{CO}_{2}$ climate. In the latter case, increasing $G$ increases the OGWD within the stratosphere, leading to the monopole structure in OGWD seen in Fig. 2a and to the associated zonal-wind weakening that drives the resolved wave response. In contrast, the OGWD response to climate change for a given $G$ represents a vertical dipole, as evident in Fig. 2d, with a correspondingly limited effect on the zonal winds (Shepherd and Shaw 2004). The same limitation then applies to the role of OGWD differences in the climate change response, implying a limited effect of OGWD response differences on the zonal wind. Instead, as shown by SS10, the difference in the zonal wind responses to climate change is primarily the result of the different resolved wave response for different climatological basic states. In particular, the tropospheric warming associated with $\mathrm{CO}_{2}$ doubling leads to changes in the basic state that reduce the barrier to equatorward propagation of planetary waves for the $G=0.25$ but not the $G=1.0$ case, leading to a reduced equatorward EP-flux response to climate change in the $G=1.0$ compared to the $G=0.25$ case. This explains not only the increased resolved wave driving response at high latitudes in the $G=1.0$ case (thus accounting for the lack of high-latitude compensation identified here), but also the midlatitude compensation 


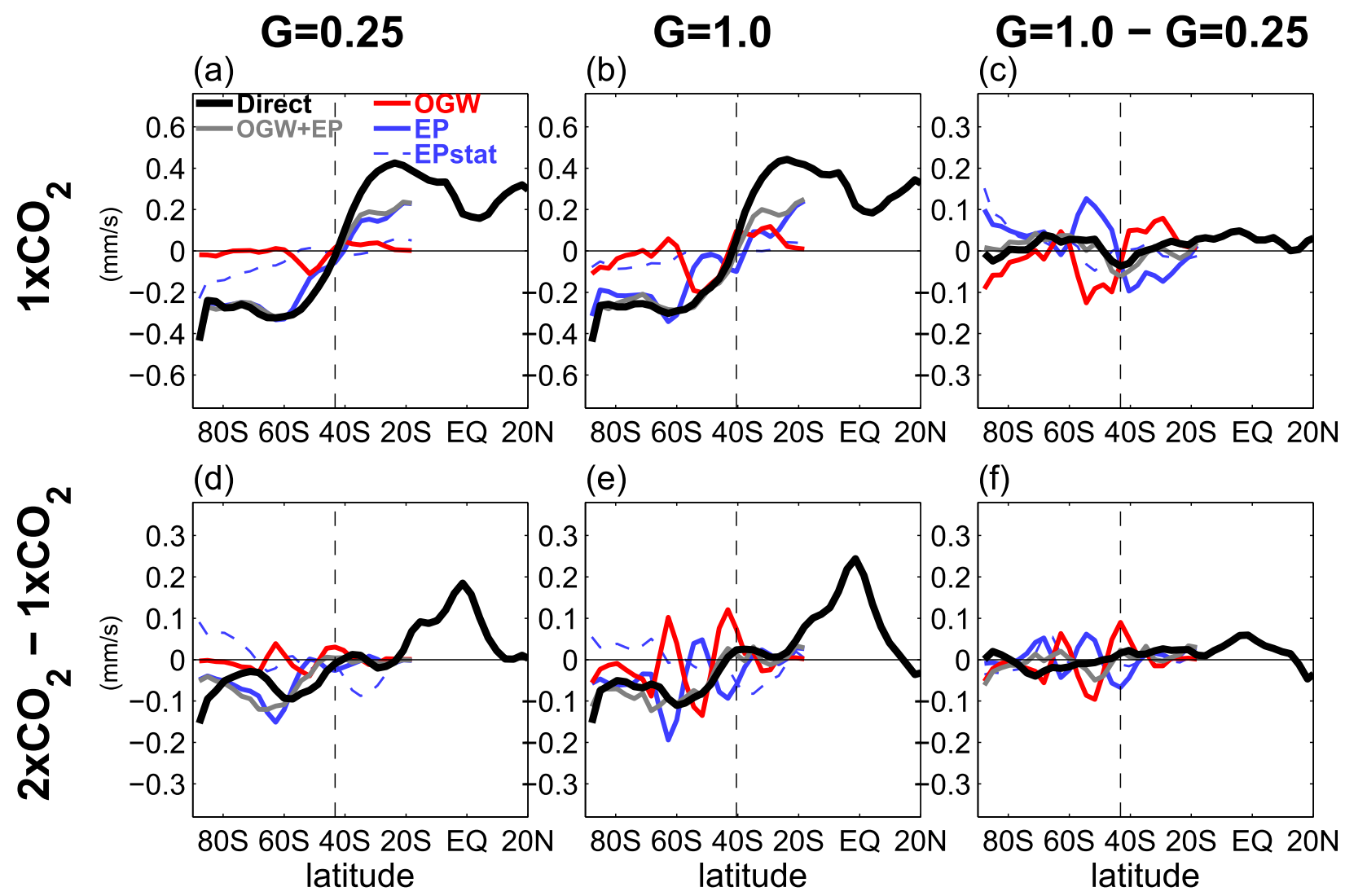

FIG. 5. As in Fig. 1, but for SH spring (SON).

itself. That the changes in the zonal wind response (contours in Fig. 3b) are the cause rather than the result of the differences in the OGWD response (shading in Fig. 3b), as shown explicitly by SS10, is evident from the fact that the zonal wind response strengthens equatorward of about $35^{\circ} \mathrm{N}$, inducing the OGWD response to shift upward, whereas the change in the OGWD response itself (which increases in the subtropical lower stratosphere; see Fig. 2d) would instead result in a weaker zonal wind response. These strengthened subtropical lower stratospheric wind responses also raise the critical levels of the resolved waves propagating up from below, allowing more EP flux to enter the lower boundary of the box delineated in Fig. $3 \mathrm{~b}$ and providing a negative resolved wave feedback that mitigates the overall degree of compensation. This negative feedback may explain why the compensation is only partial for the response to climate change.

Our results raise the question whether the compensation reflects fundamental dynamical constraints. While the EP flux budgets provide some insight in the dynamical mechanisms, the identification of the fundamental cause of compensation will require additional experiments and is left for further investigation. We note, however, that it is perhaps not surprising that the strong interaction between resolved and parameterized waves found at midlatitudes does not occur at high latitudes as at those latitudes the strength of parameterized waves is very weak.

The results of McLandress et al. (2012), obtained with the middle atmospheric extension of the model used in the current study, seem to point to a similar compensation in the SH winter and spring. They introduced an orographic gravity wave source around $60^{\circ} \mathrm{S}$ and found that the resulting OGWD was accompanied by decreased resolved wave driving. However, a closer inspection of their results reveals increases in resolved wave driving in the regions south and north of $60^{\circ} \mathrm{S}$, which indicates a latitudinal spreading of the resolved wave drag instead of a compensation. Indeed, a comparison between Figs. 16b and 16d of McLandress et al. (2012) shows that averaged over $40^{\circ}-$ $80^{\circ} \mathrm{S}$ in winter and early spring, the resolved wave drag response to the increased OGWD is close to zero. This suggests that compensation does not occur in the driving of the $\mathrm{SH}$ part of the BDC, at least, in response to an OGWD forcing at $60^{\circ} \mathrm{S}$. By contrast, we find that an increase of $G$ from 0.25 to 1.0 in austral spring [September-November (SON)], which causes an OGWD increase that maximizes around $40^{\circ} \mathrm{S}$, is accompanied by a nearly identical but opposite change by resolved waves (Fig. 5), both for the 
present-day climate and the response to climate change. This indicates that the degree of compensation critically depends on the location of the OGWD perturbation.

The results presented here have implications for the robustness of the model-predicted strengthening of the BDC under climate change. If the resolved wave drag and parameterized OGWD operated independently, then the uncertainties in each component would be additive, and the wide range of relative wave drag contributions found across current climate models (Butchart et al. 2010, 2011) would imply a large uncertainty in the modeled BDC response to climate change, despite the fact that models tend to agree on the magnitude of that response. However, we have presented evidence that there is a strong compensation between the two components. Our results thus strongly suggest that the total uncertainty on the overall $\mathrm{BDC}$ response may be significantly smaller than the uncertainties of the individual wave drag components, and hence raise the confidence in the credibility of climate model projections of the strengthened BDC.

Acknowledgments. A significant part of this work was made possible through funding to the University of Toronto by the Canadian Foundation for Climate and Atmospheric Sciences through the C-SPARC project, with additional institutional support from the Canadian Centre for Climate Modelling and Analysis, which provided the model code and supercomputing time. We thank Charles McLandress, John Scinocca, Edwin Gerber, and three anonymous reviewers for their insightful comments.

\section{REFERENCES}

Butchart, N., and A. A. Scaife, 2001: Removal of chlorofluorocarbons by increased mass exchange between the stratosphere and troposphere in a changing climate. Nature, 410, 799-802, doi:10.1038/35071047.

— the strength of the Brewer-Dobson circulation. Climate Dyn., 27, 727-741, doi:10.1007/s00382-006-0162-4.

_ , and Coauthors, 2010: Chemistry-climate model simulations of twenty-first century stratospheric climate and circulation changes. J. Climate, 23, 5349-5374, doi:10.1175/2010JCLI3404.1.

_- and Coauthors, 2011: Multimodel climate and variability of the stratosphere. J. Geophys. Res., 116, D05102, doi:10.1029/ 2010JD014995.

Cohen, N. Y., E. P. Gerber, and O. Bühler, 2013: Compensation between resolved and unresolved wave driving in the stratosphere: Implications for downward control. J. Atmos. Sci., 70, 3780-3798, doi:10.1175/JAS-D-12-0346.1.

Haynes, P. H., M. E. McIntyre, T. G. Shepherd, C. J. Marks, and K. P. Shine, 1991: On the "downward control" of extratropical diabatic circulations by eddy-induced mean zonal forces. J. Atmos. Sci., 48, 651-678, doi:10.1175/1520-0469(1991)048<0651: OTCOED $>2.0 . \mathrm{CO} ; 2$.

Hegglin, M. I., and T. G. Shepherd, 2009: Large climate-induced changes in ultraviolet index and stratosphere-to-troposphere ozone flux. Nat. Geosci., 2, 687-691, doi:10.1038/ngeo604.
Holton, J. R., 1990: On the global exchange of mass between the stratosphere and troposphere. J. Atmos. Sci., 47, 392-395, doi:10.1175/1520-0469(1990)047<0392:OTGEOM>2.0.CO;2.

Kushner, P., and L. Polvani, 2004: Stratosphere-troposphere coupling in a relatively simple AGCM: The role of eddies. J. Climate, 17, 629-639, doi:10.1175/1520-0442(2004)017<0629: SCIARS $>2.0 . \mathrm{CO} ; 2$.

Li, F., J. Austin, and J. Wilson, 2008: The strength of the BrewerDobson circulation in a changing climate: Coupled chemistryclimate model simulations. J. Climate, 21, 40-57, doi:10.1175/ 2007JCLI1663.1.

_ R. S. Stolarski, S. Pawson, P. A. Newman, and D. Waugh, 2010: Narrowing of the upwelling branch of the BrewerDobson circulation and Hadley cell in chemistry-climate model simulations of the 21st century. Geophys. Res. Lett., 37, L13702, doi:10.1029/2010GL043718.

McLandress, C., and N. A. McFarlane, 1993: Interactions between orographic gravity wave drag and forced stationary planetary waves in the winter Northern Hemisphere middle atmosphere. J. Atmos. Sci., 50, 1966-1990, doi:10.1175/ 1520-0469(1993)050<1966:IBOGWD>2.0.CO;2.

_ , and T. G. Shepherd, 2009: Simulated anthropogenic changes in the Brewer-Dobson circulation, including its extension to high latitudes. J. Climate, 22, 1516-1540, doi:10.1175/ 2008JCLI2679.1.

,-- S. Polavarapu, and S. R. Beagley, 2012: Is missing orographic gravity wave drag near $60^{\circ} \mathrm{S}$ the cause of the stratospheric zonal wind biases in chemistry-climate models? J. Atmos. Sci., 69, 802-818, doi:10.1175/JAS-D-11-0159.1.

Randel, W. J., R. Garcia, and F. Wu, 2008: Dynamical balances and tropical stratospheric upwelling. J. Atmos. Sci., 65, 3584-3595, doi:10.1175/2008JAS2756.1.

Scinocca, J. F., and N. A. McFarlane, 2000: The parametrization of drag induced by stratified flow over anisotropic orography. Quart. J. Roy. Meteor. Soc., 126, 2353-2393, doi:10.1002/ qj. 49712656802 .

,,-- M. Lazare, J. Li, and D. Plummer, 2008: The CCCma third generation AGCM and its extension into the middle atmosphere. Atmos. Chem. Phys., 8, 7055-7074, doi:10.5194/ acp-8-7055-2008.

Shepherd, T. G., 2007: Transport in the middle atmosphere. J. Meteor. Soc. Japan, 85, 165-191, doi:10.2151/jmsj.85B.165.

_ 2008: Dynamics, stratospheric ozone, and climate change. Atmos.-Ocean, 46, 117-138, doi:10.3137/ao.460106.

—, and T. A. Shaw, 2004: The angular momentum constraint on climate sensitivity and downward influence in the middle atmosphere. J. Atmos. Sci., 61, 2899-2908, doi:10.1175/ JAS-3295.1.

_ , and C. McLandress, 2011: A robust mechanism for strengthening of the Brewer-Dobson circulation in response to climate change: Critical-layer control of subtropical wave breaking. J. Atmos. Sci., 68, 784-797, doi:10.1175/ 2010JAS3608.1.

Sigmond, M., and J. F. Scinocca, 2010: The influence of the basic state on the Northern Hemisphere circulation response to climate change. J. Climate, 23, 1434-1446, doi:10.1175/ 2009JCLI3167.1.

,-- , and P. J. Kushner, 2008: Impact of the stratosphere on tropospheric climate change. Geophys. Res. Lett., 35, L12706, doi:10.1029/2008GL033573.

WMO, 2011: Scientific assessment of ozone depletion: 2010. WMO Global Ozone Research and Monitoring Project Rep. 52, 516 pp. 